\title{
Renewable Hydrogen Produced from Different Renewable Feedstock by Aqueous-Phase Reforming Process
}

\author{
Yi Wei, Hanwu Lei*, Yupeng Liu, Lu Wang, Lei Zhu, Xuesong Zhang, Gayatri Yadavalli, \\ Birgitte Ahring, Shulin Chen \\ Department of Biological Systems Engineering, Washington State University, Richland, USA \\ Email:
}

Received 6 March 2014; revised 3 May 2014; accepted 16 May 2014

Copyright (C) 2014 by authors and Scientific Research Publishing Inc.

This work is licensed under the Creative Commons Attribution International License (CC BY).

http://creativecommons.org/licenses/by/4.0/

(c) (i) Open Access

\section{Abstract}

Aqueous phase reforming (APR) of biomass derived feedstock producing hydrogen was reviewed. The APR process was discussed based on different feedstock categories such as sugars, polyols and ethanol. The mechanism of APR was analyzed referring to different structures of feedstock. The reaction pathways of APR were investigated. The usage of catalysts should be judged by feedstock on the requirement including $\mathrm{C}$-C bond cleavage, water-gas shift (WGS) reaction, and catalyst maintenance. The prospects were concluded based on the recent works from bimetallic catalysts and high efficient supports. Examples of significant challenges of reducing catalyst cost and increasing catalyst stability have been discussed. The modification and utilization of alkane selectivity of APR processes for liquid fuel production was also investigated.

\section{Keywords}

Aqueous Phase Reforming, Hydrogen, Renewable Feedstock

\section{Introduction}

As petroleum is playing a major role in world economy, rapid growing consumption of fossil fuels and depletion of total crude-oil reservations lead to global energy crisis [1]-[3]. Meanwhile, fossil fuel causes huge negative impact on environment and public health due to its pollutant gas emission [3] [4]. The increasing emission of greenhouse gas introduced by burning fossil fuel leads to global warming, which has become one of the biggest environmental issues in human history [3] [5]. Hydrogen has been recognized as promising devices to replace

\footnotetext{
*Corresponding author.
}

How to cite this paper: Wei, Y., et al. (2014) Renewable Hydrogen Produced from Different Renewable Feedstock by Aqueous-Phase Reforming Process. Journal of Sustainable Bioenergy Systems, 4, 113-127. 
the fossil fuel and meet future energy needs. Fuel cells based on hydrogen is environmentally clean, quiet, and efficient in energy conversion and power generation [4]-[6].

Although hydrogen is friendly to the environment, currently most mature hydrogen producing methods require high-temperature steam to reform non-renewable resource such as fossil fuel and natural gas [6]. The water splitting method using water as feedstock at low temperature requires high energy cost and electrolyzer systems. In order to decrease the dependence on fossil fuel and high energy cost, renewable biomass has been selected as the most attractive and potential feedstock. Biomass is the living matter who transforms the solar energy in chemical style and stores in creatures through photosynthesis process [7]. Biomass feedstock has strong potential in energy production due to its sustainability and positive environmental relationship [8]. Generally, renewable biomass feedstock includes crops, wood, wood waste, agriculture waste, municipal solid waste, animal waste, food processing waste and algae [9]. The major components of cellulosic biomass include cellulose, hemicellulose and lignin, with minor protein, ash, starch and other components. Cellulose and hemicellulose are formed with complex polysaccharides, while lignin consists of highly substituted and mononuclear phenolic amorphous [3]. Traditional biomass, mainly cellulosic biomass, combusts directly and has supported 7\% $11 \%$ of the world's energy needs [9]-[11].

To make the most of the feedstock, a variety of hydrogen technologies based on renewable biomass feedstock has been developed. Among these technologies, gasification, fermentation, microbial electrolysis cells, and aqueous phase reforming (APR) have great potential and gain significant development [12]. As side reactions caused by high temperature will decrease the selectivity of hydrogen, gasification is not suitable for the long term development of biomass-based hydrogen production [13]-[16]. Fermentation has been commercialized, while its limits in organic acids inhabitation, high energy cost and product re-oxidation still have not been solved [12]. Microbial electrolysis cell has a strong potential but still stumbling in research stage due to its instability and cell reversal [16].

Aqueous phase reforming (APR) was introduced by Dumesic and co-workers at the first time in 2002 [14]. APR process produces hydrogen and other value-added chemicals from biomass derived feedstock in a significantly mild reaction condition at a temperature around $500 \mathrm{~K}$ [17]. It can take place in a single chemical reactor system though the process concludes various reversible chemical reactions like water-gas shift (WGS) reaction, dehydration, carbon bond cleavage, etc [18] [19]. The C-C bonds in the feedstock cleavage on the metal catalyst produce carbon monoxide and hydrogen, in subsequent WGS reaction [6] [17] [19]. Davda et al. reported a low-temperature exothermic reaction of WGS in APR process, indicating a lower temperature desirable, which could combine with steam reforming and significantly reduce energy consumption [6] [17]. Intermediate oxygenates undergo dehydrations by combining both C-C bonds and C-O bond cleavage reactions on acid sites of the catalyst support, and convert to C1 to C6 alkanes through hydrogenation on metal catalyst surface [18] [20]-[23].

Interests in using APR process to produce hydrogen have grown strongly recently due to its significant advantage over other methods. First, as mentioned above, APR process occurs at a relatively low temperature, which benefits the hydrogen production on two aspects. On one hand, lower temperature reduces the energy requirement during hydrogen production remarkably [17]-[23]. On the other hand, lower reaction temperature reduces the undesirable products by both minimizing the high temperature thermal chemical reactions and promoting WGS process of carbon monoxide transition [15] [19]. Second, APR process takes place in liquid phase, indicating unnecessary to remove the water from the biomass feedstock, by which reduces the cost during the hydrogen production [6]. The third advantage comes from the friendly processes to the environment. Compared with other methods, APR uses renewable biomass derived chemicals as feedstock, takes reactions at mild conditions, and produces hydrogen or other chemicals, which are renewable, too [20] [25]. Both biomass derived polyols like sorbitol and hydrogen and alkane products are nontoxic [6]. Besides, a single-step chemical reactor system can afford for whole APR process allowing simplified process and low energy consumption [18].

APR process was closely related to the reaction factors, such as metal catalysts, catalyst supports, feeds, and reaction conditions [18]. Although substrate structures have strong influence on APR process, various researches have been conducted on medal catalysts and catalyst supports based on single feedstock [26]-[31] and few of them refers to feedstock comparison [25]. This review focuses on APR catalysts, APR mechanism and APR kinetic study based on substrate categories, which will contribute to further study on feedstock selection and production of renewable clean fuels by APR process. 


\section{Sugar Based Aqueous Phase Reforming}

\subsection{Glucose}

Glucose is one of the most popular feedstock and draws many attentions for the reason that the sugar works as the major natural energy reserves [32]. Compared with other biomass derived feedstock, glucose has advantageously less reduction process than other biomass feedstock [6]. It can be produced from cellulose and hemicellulose by acid hydrolysis in hydrothermal ways [33]. The glucose taking APR process follows the equations below.

$$
\mathrm{C}_{6} \mathrm{H}_{12} \mathrm{O}_{6}+6 \mathrm{H}_{2} \mathrm{O} \rightarrow 12 \mathrm{H}_{2}+6 \mathrm{CO}_{2}
$$

Glucose first reacts at C-C bonds cleavage on the metal side of the catalyst [32]. During each cleavage of C-C bonds, one molecule of carbon monoxide and one molecule of hydrogen are formed. The carbon monoxide performs as an intermediate product, which followed by WGS and produces one molecule of hydrogen and one molecule of carbon dioxide. The key to avoid undesirable hydrogen consuming reactions in the process is the selectivity of C-C bonds cleavage [34]. Davda et al. reported that unwanted reactions like Fischer-Tropsch reaction took place on the acid side of the catalyst, resulting in a high alkane content rather than hydrogen [32]. Kim et al. also found that methanation occurred during the APR process [18]. Both reactions due to unwanted C-O bonds cleavage result in a lower hydrogen concentration in the final products.

Researches have been conducted on temperature influence on C-C bonds cleavage. Gursahani et al. built density function theory and illustrated that $\mathrm{C}-\mathrm{C}$ bonds in glucose are adsorbed on platinum on its most at a temperature around $200^{\circ} \mathrm{C}$ [35]. Higher temperature $\left(220^{\circ} \mathrm{C}\right)$ will cause hydrogenated aromatic ethers and ester groups. These intermediates will not take further APR process [34]. However, lower temperature will lead to a preferable C-O bonds cleavage [32]. The temperature and the selectivity of C-C bond cleavage are the main limitations for APR process. To seek a better selectivity, a variety of catalysts have been used in the APR process [6] [18] [24] [28] [32]-[34] [36] [37]. The first used catalyst in hydrogen production by APR was nickel. Minowa et al. [36] used Ni metal with different supports and conducted series of experiments at temperatures ranging from $200^{\circ} \mathrm{C}$ to $350^{\circ} \mathrm{C}$. Their results showed a high gas yield in the research with high methane content and less hydrogen content, indicating that $\mathrm{Ni}$ only contributed to gasification as it had lower selectivity on C-C bonds cleavage. Minowa et al. attributed that the low hydrogen yield was due to the different particle sizes of the feedstock and catalyst, as glucose had a bigger molecular size than nickel particles presented on external surfaces. Their high methane yield on silicon support also strongly proved that the acidic side would contribute to methanation process [36].

Tanksale et al. [37] used $\mathrm{Pt} / \mathrm{Al}_{2} \mathrm{O}_{3}$ catalysts on glucose mixture at temperatures from $185^{\circ} \mathrm{C}$ to $220^{\circ} \mathrm{C}$. The platinum showed a better selectivity on $\mathrm{C}-\mathrm{C}$ bond cleavage rather than $\mathrm{C}-\mathrm{O}$ bond cleavage, resulting in more active hydrogen production than nickel catalysts. Nearly $0.4 \mathrm{~mL} / \mathrm{min}$ rate of hydrogen formation was obtained in their research at the temperature of $200^{\circ} \mathrm{C}$. The results at $220^{\circ} \mathrm{C}$ strongly support the significant temperature influence. Same catalyst has been applied in Davda et al. [32]'s research, which ran the experiments using 10 wt\% glucose solutions at $260^{\circ} \mathrm{C}$ and 52.4 bar. Only $13.4 \%$ of hydrogen selectivity was found while alkane selectivity reached nearly $50 \%$, which indicates that $\mathrm{C}-\mathrm{O}$ bond cleavage was much more desirable than $\mathrm{C}-\mathrm{C}$ bond cleavage [32].

Compared with other feedstock, glucose had quite lower hydrogen selectivity than other feedstock even using the same catalyst [6] [32] [34]. This is because glucose is not stable in aqueous solutions and undergoes isomerization reaction and further decomposition reaction. These undesirable homogeneous reactions usually have prior order than APR process [21]. Kabyemela et al. reported that fructose, dihydroxyacetone, glyceraldehyde, pyruvaldehyde, acetic acid, formic acid and 5-hydroxymethyl-2-furfural (HMF) were found in glucose solution, resulting in less than $10 \mathrm{wt} \%$ increase in liquid concentration, while the hydrogen selectivity of glucose was decreased [38]. Cortright et al. supported the point and showed a deeper influence when temperature was raised [14]. The decrease of hydrogen selectivity from glucose limits the APR process by excessive amount of water [32] [38]. As a result, though performs as a major energy reserves, glucose is not the most suitable feedstock for APR process.

\subsection{Fructose}

Fructose is widely found in nature and works as an important monosaccharide to form sucrose [38]. Many re- 
searches have been focused on fructose isomerization [39] and hydrogenation to mannitol in food industry [39] [40]. The researches on dehydration process of fructose aim to produce value-added chemicals such as HMF [38] [39], but seldom of researches conducted on clean fuel and hydrogen production by fructose dehydrogenation.

Fructose has a similar mechanism to glucose in APR process. The fructose molecule will take C-C bonds cleavage on metal site of catalyst after two hydrogen molecules formed. The cleavage process results in $\mathrm{CH}-\mathrm{OH}$ group and acetic acid formation. Furthermore, $\mathrm{CH}-\mathrm{OH}$ group is dehydrogenated again and gives hydrogen and carbon monoxide, which is followed by WGS and produces one molecule of hydrogen and one molecule of carbon dioxide [37]. As a limitation to the process, C-O bond cleavage occurs on weak acid sites of the catalyst and produces undesirable products such as 4-oxopentanoic acid butan-2-one [41].

Kabyemela et al. [37] had conducted APR of fructose in batch reactor using $\mathrm{Pt}_{2} / \mathrm{Al}_{2} \mathrm{O}_{3}$ catalyst and obtained over $2 \mathrm{~mL} / \mathrm{min}$ of hydrogen formation rate at the temperature of $220^{\circ} \mathrm{C}$. They concluded that their APR process has high dehydrogenation rate and low WGS reaction rate. Another interesting result different from glucose feedstock showed that accumulation of 2-furaldehyde during high concentration hydrogen production in reactors draws much attention. A reasonable interpretation for the result is hydrogenation of catalytic adsorbed fructose molecules [37]. To obtain higher hydrogen formation, hydrogen product should be removed from the reactor before hydrogenation process.

Fructose has a better performance and less undesirable products than glucose on APR process. However, as an important feedstock for food industry, fierce competitions will be foreseen between food and energy [39] [40]. Moreover, value-added product like HMF have advantages on profit than hydrogen product [38], which may also limits the development of APR process of fructose feedstock.

\section{Polyols Based Aqueous Phase Reforming}

\subsection{Sorbitol}

Sorbitol is one of the most attractive biomass derived resources for APR process since last decade and has been selected as one of top 12 high value-added intermediate chemicals [42] [43] Current production of sorbitol estimated at 1.2 million tons per year, which was mainly produced by catalytic hydrogenation of glucose [17] [44]-[46]. Sorbitol has advantages on APR process as it has quite same numbers of C-C and C-O bonds [42]. The sorbitol undergoing APR process obeys the equations below.

$$
\mathrm{C}_{6} \mathrm{H}_{14} \mathrm{O}_{6}+6 \mathrm{H}_{2} \mathrm{O} \rightarrow 13 \mathrm{H}_{2}+6 \mathrm{CO}_{2}
$$

The pathway of APR process of sorbitol has been investigated approximately the same as glucose [44]. Each time when C-C bond cleavages occurs, one molecule of carbon monoxide and hydrogen are formed, with directly formed one molecule of carbon dioxide and extra hydrogen. Another reaction mechanism studied by Aiouache et al. [25] presented an intermediate during the APR process of sorbitol. In their lumping pathway, the sorbitol was converted to generic intermediates $\left(\mathrm{C}_{\mathrm{x}} \mathrm{H}_{\mathrm{y}} \mathrm{O}_{\mathrm{z}}\right)$ at first, then formed hydrogen and carbon dioxide via WGS. Whichever the pathway undergoes, the most significant advantage of sorbitol over glucose feedstock is that homogeneous side reactions have been successfully reduced [6] [25]. Davda et al. [6]'s result on APR process using glucose and sorbitol as feedstock gave $13 \%$ to $60 \%$ hydrogen selectivity under the same reaction conditions. Their following research [32] on glucose co-feed with hydrogen obtained $62.4 \%$ hydrogen selectivity by converting glucose to sorbitol at lower temperature under hydrogen atmosphere before APR process. The result that sorbitol did not undergo dehydrogenation to glucose without co-fed hydrogen was also found, indicating a more stable feedstock in water-phase [32].

Though sorbitol does not take homogeneous side reactions, it is important that the selectivity of C-C bonds cleavage is increased. APR process via $\mathrm{Pt} / \mathrm{Al}_{2} \mathrm{O}_{3}$ catalyst at $498 \mathrm{~K}$ and $538 \mathrm{~K}$ had over $60 \%$ hydrogen selectivity [6]. Huber et al. reported Raney-Ni-Sn catalysts with Ni-Sn atomic ratios of up to 14:1 had comparable effect to the Pt catalyst [47]. Aiouache et al. [25] tested six different catalysts on sorbitol APR process and analyzed the reaction kinetics based on Ni catalyst and different supports. The activation energy combining the C-C cleavage and WGS reaction was $26.4 \mathrm{kcal} / \mathrm{mol}$ [21] [25]. Ni catalysts showed low hydrogen selectivity in the experiment, while Pd catalyst had a better performance though limited WGS. Among six catalysts, $4.75 \% \mathrm{Ni}-0.25 \% \mathrm{Pd} /$ $\mathrm{CeO}_{2}$ had the best WGS constants rate [25].

Larger in molecule size than glycerol and ethylene glycol, sorbitol revealed more complicated APR process reactions [44]. Kirilin et al. [48] reported 75\% hydrogen selectivity was achieved at 2.7 of weight hour space 
velocity (WHSV) via $\mathrm{Pt} / \mathrm{Al}_{2} \mathrm{O}_{3}$ catalyst, much less than using xylitol as feedstock, due to oxygenated intermediates adsorbed on Platinum surface, while keeping gasification conversions. The adsorption during the APR process influenced the catalyst performance by reducing the hydrogen selectivity. As a result, sorbitol has more limitations for APR process compared with other biomass derived polyols. Nevertheless, as glucose derived polyols, sorbitol has great potentials in APR process of hydrogen production.

\subsection{Xylitol}

Xylitol is a five-carbon polyols derived from xylose of hemicellulose and also has been selected as one of top 12 high value-added intermediate chemicals [49]. It is produced by chemical hydrogenation process via nickel catalyst [50]. However, though ranked as the second most abundant polyols, few studies have been conducted on APR process using xylitol. Making the most use of the xylitol from hemicellulose rich hardwood species will be important, as it opens new horizon for hemicellulose transition to clean hydrogen fuels [25]. The xylitol undergoing APR process follows the equations below.

$$
\mathrm{C}_{5} \mathrm{H}_{12} \mathrm{O}_{5}+5 \mathrm{H}_{2} \mathrm{O} \rightarrow 11 \mathrm{H}_{2}+5 \mathrm{CO}_{2}
$$

The APR process of xylitol follows the C-C bond cleavage rule reported in sorbitol transformation [51]. Xylitol undergoes dehydrogenation of terminal $\mathrm{OH}$ group to produce ketone intermediate, with subsequent evolution of CO and WGS to produce one carbon molecule polyols intermediate. With carefully controlled reaction conditions, the dehydrogenation and WGS repeat three more times and produce hydrogen and carbon dioxide [51]. The side reaction occurs under high hydrogen content. The C-O bonds cleavage occurs when ketone intermediate was continuously dehydrogenated and hydrolyzed to form polyol acids. These acids will further take $\mathrm{C}-\mathrm{O}$ bonds cleavage and consume hydrogen, resulting in complex compositions of product, such as linear alcohols, diols, ethers, ketone and acid [25]. Hydrogen atmosphere also leads to HMF and pentane production [22] [25] [47].

The key to minimizing the side reactions and increasing the selectivity of hydrogen is to increase the conversion of xylitol and using high hydrogen selectivity catalyst. Jiang et al. [52] conducted groups of research and indicated that catalytic process at near $227^{\circ} \mathrm{C}$ could produce hydrogen on APR process. Kirilin et al. [25] reported $100 \%$ conversion at WHSV of $1.5 \mathrm{~h}^{-1}$ and $83 \%$ hydrogen selectivity using $\mathrm{Pt} / \mathrm{Al}_{2} \mathrm{O}_{3}$ as catalyst. They also found that hydrogen yield increased when WHSV was decreased, and the highest yield was reached at $32 \%$ compared to $21 \%$ of sorbitol, which was obtained at $225^{\circ} \mathrm{C}, 29.3 \mathrm{bar}, 10 \mathrm{wt} \%$ polyols solution, and $30 \mathrm{~mL} / \mathrm{min}$ nitrogen flow rate. The considerable low yield at high WHSV was caused by hydrogen consuming in more active inevitable side-reactions.

Another research by Kirilin and his co-authors [47] reported an APR process of xylitol via different catalysts. Compared the three catalysts in their research, $\mathrm{Pt} / \mathrm{Al}_{2} \mathrm{O}_{3}$ had the strongest hydrogen selectivity and $\mathrm{Pt}-\mathrm{Re} / \mathrm{TiO}{ }_{2}$ had the best xylitol conversion, while $\mathrm{Pt} / \mathrm{TiO}_{2}$ did not need regeneration and had good performance on alkane selectivity. Xylitol has many similarities to sorbitol in APR behaviors. Moreover, abundant of hemicellulose feedstock offers a bright future on APR process.

\subsection{Glycerol}

Glycerol is a simple alcohol with three hydroxyls, which can be derived from oil rich plant seeds with fatty acids. It plays an important role in chemical industry, food industry, bio-technology industry and even pharmaceutical industry [53]. However, the rapid developing biodiesel industry had strong influence on glycerol industry in recent years and turned it to be an overproduced byproduct, as $1 \mathrm{~L}$ of glycerol was made from every $10 \mathrm{~L}$ of biodiesel produced [54]. Besides, crude glycerol from biodiesel production is costly to be refined [55]. The APR process has been conducted on glycerol with both kinetic and mechanism investigated [15] [31] [56]-[63]. The APR reaction for glycerol is described below:

$$
\mathrm{C}_{3} \mathrm{H}_{8} \mathrm{O}_{3}+3 \mathrm{H}_{2} \mathrm{O} \rightarrow 7 \mathrm{H}_{2}+3 \mathrm{CO}_{2}
$$

The APR process of glycerol is endothermic reaction [56]. As there is only $3 \mathrm{C}-\mathrm{C}$ bonds in one molecule, both glycerol and intermediate are easily reacted as small molecules, which produce a complex mixture. The complexity drives the analysis of reaction pathways difficult based on products [31]. Davda et al. [6], Zhang et al. [31] and Luo et al. [56] considered that $\mathrm{CH}-\mathrm{OH}$ groups were formed during the APR process as intermediate. 
Then the $\mathrm{CH}-\mathrm{OH}$ groups undergo dehydrogenation and produce carbon monoxide. On the opposite, Wawrzetz et al. [57] concluded that glycerol was converted to hydrogen and carbon monoxide via a glyceraldehyde step. In another word, the second dehydrogenation step took place before C-C cleavage. In any case, glycerol molecule will follow the pathway and form ethylene glycol, then methanol, if no side-reaction and C-O bonds cleavage happened during the APR process. Unfortunately, the glycerol and its intermediates are easily taking C-O bonds cleavage by hydrogenation or dehydration. If $\mathrm{C}-\mathrm{O}$ bonds cleavage occurs on glycerol, hydroxyacetone and 3-hydroxypropanal will be formed, which will be further hydrogenated to propanol or propane. The intermediates undergo C-O bonds cleavages and produce propylene glycol, which transforms to ethane [31] [56] [57]. Wawrzetz et al. [57] showed only $20 \%$ of hydrogen selectivity caused by the C-O bonds cleavage.

It is important to find applicable catalysts to increase hydrogen selection. Nickel is selected for its low price and it is widely used in hydrogen production. Guo et al. [58] worked on the Ni-B amorphous alloy nanoparticle catalyst and Raney Ni catalyst. Their experiments were set with $10 \mathrm{wt} \%$ glycerol at $498 \mathrm{~K}, 2.76 \mathrm{MPa}$ and a flow rate of $0.10 \mathrm{~mL} / \mathrm{min}$ using the two catalysts, showing that Ni-B amorphous alloy nanoparticle catalyst had higher hydrogen selectivity (77\% to $45 \%$ ), lower alkane selectivity (12\% to $23 \%$ ), and longer stably maintained time than Raney Ni catalyst. The hydrogen selectivity obtained by Shabaker et al. [28] in APR of glycerol using Sn modified Ni catalyst was $64 \%$ at $265^{\circ} \mathrm{C}$. Tuza et al. [15] reported incredible $90 \%$ of hydrogen selectivity using $\mathrm{Cu}$ modified $\mathrm{Ni}$ catalyst at $250^{\circ} \mathrm{C}$, while less than $30 \%$ of conversion rate was occurred after 12 hours. When rising the temperature to $270^{\circ} \mathrm{C}$, a maximum glycerol conversion of $60 \%$ was reached as hydrogen selectivity was dropped to $80 \%$. They also reported less than $5 \%$ carbon dioxide and methane selectivity, due to unknown reactions happened on catalysts rather than APR that consumes the carbon monoxide with $\mathrm{Cu}$ limiting the methane formation. It is highly possible for the reason that $\mathrm{Cu}$ had strong activity for WGS reaction and did not catalyze methane formation [20].

Meryemoglu et al. [59] conducted experiments on comparison between Raney Ni catalyst and Pt based catalyst for glycerol, showing a higher conversion rate and hydrogen selectivity achieved by Pt based catalyst. According to the results, Pt catalyst has a better performance on hydrogen production than Ni catalyst though its high price. Based on Pt catalyst, Ciftci et al. [60] made comparison between different catalytic supported $\mathrm{Al}_{2} \mathrm{O}_{3}$, $\mathrm{SiO}_{2}$ and amorphous silica-alumina (ASA) on APR of glycerol, and reported the highest hydrogen selectivity of over $70 \%$ obtained on $\mathrm{Pt} / \gamma-\mathrm{Al}_{2} \mathrm{O}_{3}$ catalyst at WHSV of $4.2 \mathrm{~h}^{-1}$ and $225^{\circ} \mathrm{C}$. Similar researches conducted by Menezes et al. [61] showed the same result with Ciftci et al., but indicated a better hydrogen selectivity on MgO. Based on $\mathrm{Pt} / \gamma-\mathrm{Al}_{2} \mathrm{O}_{3}$ catalyst, Copeland et al. [62] and Luo et al. [56] studied on the effect of $\mathrm{Pt} / \gamma-\mathrm{Al}_{2} \mathrm{O}_{3}$ catalyst with different metal contents. Luo et al. showed that $0.9 \mathrm{wt} \% \mathrm{Pt} / \gamma-\mathrm{Al}_{2} \mathrm{O}_{3}$ had better hydrogen generation performance at $260^{\circ} \mathrm{C}$ for 2 hours in a batch reactor, while Copeland et al. indicated that the catalyst with $5 \mathrm{wt} \% \mathrm{Pt}$ had a strong impact on the observed kinetics by ATR-IR. Futher, Özgür et al. [63] investigated optimum reaction condition of APR process of glycerol in both autoclave reactor and fixed-bed reactor based on $\mathrm{Pt} / \gamma-\mathrm{Al}_{2} \mathrm{O}_{3}$, at temperatures ranged from $160^{\circ} \mathrm{C}$ to $280^{\circ} \mathrm{C}$, feed flow rate from 0.05 to $0.5 \mathrm{~mL} / \mathrm{dak}$, and feed concentration from $5 \mathrm{wt} \%$ to $85 \mathrm{wt} \%$. They found that high temperature contributed to the conversion rate but decreased hydrogen selectivity, while higher feedstock concentration and faster flow rate over $1 \mathrm{~mL} / \mathrm{min}$ limited the hydrogen production. Their optimized reaction condition for APR process of glycerol over $\mathrm{Pt} / \mathrm{Al}_{2} \mathrm{O}_{3}$ catalyst was at $230^{\circ} \mathrm{C}$, feed flow rate around $0.73 \mathrm{~h}^{-1}$ WHSV with less than $45 \mathrm{wt} \%$ of glycerol concentration. Full utilization of overproduced glycerol will not only reduce the waste of valuable byproducts, but also add benefit on biodiesel production [53]. Glycerol will play an important role in biodiesel and hydrogen production in the near future.

\subsection{Ethylene Glycol}

Ethylene glycol is an important industry feedstock which can be derived from sustainable biomass [64]. Many studies on APR process reported using ethylene glycol for its good hydrogen selectivity [6] [64]-[70]. Ethylene glycol does not require high reforming temperature since only 2 C-C bonds in one molecule [6]. The reaction of APR process of ethylene glycol is shown below.

$$
\mathrm{C}_{2} \mathrm{H}_{6} \mathrm{O}_{2}+2 \mathrm{H}_{2} \mathrm{O} \rightarrow 5 \mathrm{H}_{2}+2 \mathrm{CO}_{2}
$$

The pathways of ethylene glycol involve hydrogen formation on metal catalyst. Similar to glycerol, ethylene glycol undergoes dehydrogenation to form intermediate adsorbed on the metal surface. The intermediate then takes $\mathrm{C}-\mathrm{C}$ bonds cleavage and forms $\mathrm{CH}-\mathrm{OH}$ groups [6] [65]. Though C-C bonds easily form stable intermediate than C-O, C-O cleavage still happens after dehydrogenation [65] [66]. Vlieger et al. [65] reported that ethanol 
and acetic acid were observed during the process. Ethanol was formed by C-O cleavage, which drove methane formation. Acetic acid was produced by rearrangement of the intermediate, which caused the formation of alkanes, even deactivating the catalyst. Vlieger et al. emphasized that all of these pathways led to the liquid byproducts and alkane formation, resulting in lower hydrogen selectivity and yield. According to their research, an effective catalyst for reforming ethylene glycol should be active for both C-C bond cleavage and WGS reaction at the same reaction condition, in order to minimize side-reactions.

Davda et al., Huber et al., Dumesic et al. [6] [14] [20] [21] [24] [26] [28] [35] [67] and co-authors have studied catalysts on APR of ethylene glycol for several years. Experiments [67] were carried out on $\mathrm{Pt} / \mathrm{Al}_{2} \mathrm{O}_{3}$ catalyst at first, at temperature of 483 and $498 \mathrm{~K}$ with different metal loadings. The rate of hydrogen production was 0.5 on ethylene glycol. Weak inhibition was found during the APR process due to catalytic surface sites blocking, resulting in lower hydrogen production rate. Meanwhile, research [20] was conducted on silica-supported, with $\mathrm{Ni}, \mathrm{Pd}, \mathrm{Pt}, \mathrm{Ir}, \mathrm{Ru}$ and $\mathrm{Rh}$ metal catalysts, at temperatures of 483 and $498 \mathrm{~K}$ and pressures of 22 bar. The result exhibited that though Pt and Pd did not reach high C-C bond cleavage activity as Ru, Ni, Ir and Rh, both of them had lower rates of methanation and higher rate of WGS reaction, resulting in a better performance on hydrogen selectivity in APR processes. Besides, silica-supported Pt and Pd were not easily deactivated at high temperature as Ni did. Pt and Pd showed great potentials on metal catalysts of APR process with further studies focusing on Pt and Pd bimetallic catalysts [26]. Over 130 metal combinations with Pt, Ni, Co, Pd and Fe were tested during the study, presenting a significant higher activity than monometallic catalyst. In their study, $\mathrm{Pt}-\mathrm{Ni} / \mathrm{Al}_{2} \mathrm{O}_{3}$ and $\mathrm{Pt}-\mathrm{Co} / \mathrm{Al}_{2} \mathrm{O}_{3}$ achieved turnover frequency for $\mathrm{H}_{2}$ production $\left(\mathrm{TOF}_{\mathrm{H} 2}\right.$ ) of $5.2 \mathrm{~min}^{-1}$, which was 3.5 times more active than $\mathrm{Pt} / \mathrm{Al}_{2} \mathrm{O}_{3}$ catalyst at $483 \mathrm{~K}$. They also mentioned that bimetallic catalyst could solve the limitation on monometallic catalyst like WGS limitation on Pd and catalyst deactivation limitation on Ni.

Many other scientists also worked on bimetallic catalysts and have obtained great success and achievement. Kim et al. [68] used Pt bimetallic catalysts with other metals on different supports, with WHSV of $2.0 \mathrm{~h}^{-1}$ at $250^{\circ} \mathrm{C}$, and $45 \mathrm{~atm}$. Pt-Mn bimetallic catalysts on CNK-3 support had the highest activity of hydrogen production among all monometallic catalysts, reaching $\mathrm{TOF}_{\mathrm{H} 2}$ of $180 \mathrm{~min}^{-1}$ at peaks. The alkane selectivity was less than 4.0\%. Chu et al. [69] exhibited $\mathrm{TOF}_{\mathrm{H} 2}$ of $101 \mathrm{~min}^{-1}$ using Co and Zn bimetallic catalysts, with WHSV of $0.59 \mathrm{~h}^{-1}$ at $498 \mathrm{~K}$, and $2.58 \mathrm{MPa}$.

As a noble metal, platinum as feedstock increases the cost on catalyst significantly. Nickel has outstanding performances in hydrogen production, but not suitable for APR process. Great efforts have been put on utilizing the hydrogen production activity and minimizing the limitations of Ni catalyst. Ni-Sn bimetallic draws much attention in recent years. Sn contributes to increasing hydrogen selectivity by promoting WGS reactions and turning the catalyst not being sensitive to WHSV and pressure [64]. Dumesic et al. [28] tested the different ratio of Ni-Sn bimetallic catalysts at $483 \mathrm{~K}$ and obtained $74 \%$ hydrogen selectivity and $94.1 \mu \mathrm{mol} \cdot \mathrm{g}^{-1} \mathrm{cat} \mathrm{min}^{-1}$ at the first run. However, the Ni-Sn catalyst was deactivated quickly when running for long time due to highly dispersed metal particles sintered. The sintered particles decreased the surface area and limited the carbon monoxide uptake. Meanwhile, the hydration of $\mathrm{Ni}$ oxide leads to a mass loss on catalyst. To solve the problem, Pan et $a l$. [70] combined $\mathrm{Al}$ hydrotalcite as a catalyst support. By using $\mathrm{Al}$ hydrotalcite, the catalyst could maintain $85 \%$ of the highest hydrogen producing rates and selectivity for $120 \mathrm{hr}$. Ni-Snbimetallic offers a bright pathway to achieve the goal.

\section{Ethanol Based Aqueous Phase Reforming}

It is well-known that ethanol produced from fermentation followed by distillation from bio-renewable sources has been commercialized [24]. Compared with polyols, ethanol is not the optimum feedstock for APR process for the reason that it requires more steps in conversion from raw biomass to hydrogen [71]. Nevertheless, hydrogen production from ethanol by APR process not only exhibits a potential way to produce hydrogen, but also appears to be important for solving the technical problem during APR process of glycerol and ethylene glycol, as ethanol was formed as byproducts [35] [56] [65] [72]. The APR pathway of ethanol can be totally different in product as it does not have equal number of carbon and oxygen atoms [35].

$$
\mathrm{C}_{2} \mathrm{H}_{6} \mathrm{O}+\mathrm{H}_{2} \mathrm{O} \rightarrow 2 \mathrm{H}_{2}+\mathrm{CO}_{2}+\mathrm{CH}_{4}
$$

The possible reaction steps have been studied by researchers [73]-[75]. Ethanol first dehydrogenated to form acetaldehyde. From the acetaldehyde intermediate, two possible reactions can happen. The first pathway comes when the $\mathrm{C}-\mathrm{C}$ bond in acetaldehyde cleaves directly and produces methane and carbon monoxide, followed by 
WGS. On the second pathway, acetaldehyde undergoes hydration and results in formation of hydrogen and acetic acid. Then the acetic acid takes C-C bond cleavage and produces methane and carbon dioxide. Similar pathways were also identified by Nozawa et al. [72], which was strongly supported by Roy et al. As the second pathway was found, it is possible for ethanol to form carbon dioxide without WGS reaction. High concentration of carbon dioxide and hydrogen will drive the WGS reaction backward to form carbon monoxide and water [73]. As a result, the catalyst used in APR process of ethanol requires high ethanol conversion percentage, strong stability and special limitation on backward WGS reaction, rather than selectivity among C-C bond and C-O bond. Research conducted by Tokarev et al. [71] over $\mathrm{Pt} / \mathrm{Al}_{2} \mathrm{O}_{3}$ at $225^{\circ} \mathrm{C}$ exhibited a high conversion of $98 \%$ but less effective on ethanol while that $\mathrm{Pt} / \mathrm{SiO}_{2}$ had a poor effect on ethanol [35].

Both of the research mentioned above did not take the second pathway into consideration and treated acetic acid as an inactive intermediate. During the second pathway, hydration of acetaldehyde to acetic acid releases large amount of heat and raises the temperature of reaction systems, which contribute to the decomposition of acetaldehyde. The increasing concentration of carbon monoxide drives the WGS reaction to form hydrogen and carbon monoxide [74]. $\mathrm{Ru} / \mathrm{TiO}_{2}$ was applied on APR process of ethanol and achieved $\mathrm{TOF}_{\mathrm{H} 2}$ of $56.4 \mathrm{~min}^{-1}$ at $473 \mathrm{~K}$. Formation of $\mathrm{CH}_{4}$ and $\mathrm{CO}$ in nearly 1:1 ratio was observed during the experiment, indicating completely conversion of ethanol and less side-reaction. Nozawa et al. [72] attributed the consequence of high activity of $\mathrm{Ru}$ catalyst on acetaldehyde to acetic acid transition and promoted the WGS reaction forward. Roy et al. [73]-[75] applied $\mathrm{Ni}$ with $\mathrm{Al}_{2} \mathrm{O}_{3}$ support on APR process of ethanol, and obtained over $90 \%$ of hydrogen selectivity and $\mathrm{TOF}_{\mathrm{H} 2}$ of $12 \mathrm{~h}^{-1}$. Their work exhibited a strong promotion on acetaldehyde to acetic acid transition by solution combustion synthesis of $\mathrm{Al}_{2} \mathrm{O}_{3}$. They also presented that small particles of metal catalyst contributed to higher $\mathrm{TOF}_{\mathrm{H} 2}$. Acetic acid deactivated the catalyst during APR of sorbitol, glycerol and ethylene glycol, but it did not occur during APR of ethanol [71]. Obviously, the key to a successful APR process of ethanol is controlling the acetaldehyde intermediates.

\section{Other Bio-Renewable Feedstock Based Aqueous Phase Reforming}

\subsection{Methanol}

Methanol is one of biomass-derived oxygenated hydrocarbons [67]. It is the simplest monohydric alcohol in nature. It only contains C-O bond but no C-C bond. The methanol can take APR process according to the stoichiometric equation below.

$$
\mathrm{CH}_{4} \mathrm{O}+\mathrm{H}_{2} \mathrm{O} \rightarrow 3 \mathrm{H}_{2}+\mathrm{CO}_{2}
$$

Two opposite viewpoints have been set up on APR process of methanol. Shabaker et al. [67] thought APR process of methanol had very similar reactivity to the ethylene glycol over $\mathrm{Pt} / \mathrm{Al}_{2} \mathrm{O}_{3}$ catalysts. It had the highest hydrogen producing order than other feedstock. The reason for low hydrogen yield is the limitation by hydrogen. The hydrogen filled the surface site of the catalyst and prevented the dehydrogenation of methanol. Xie et al. [76] considered methane selectivity was higher than hydrogen selectivity and suppressed methanation could obtain higher hydrogen selectivity at $500 \mathrm{~K}$. Xie et al. also put forward another reaction by which methanol was decomposed to carbon and hydrogen directly, which contributed to the formation of hydrogen at lower temperature. In any case, methanol does not show good hydrogen yield on APR process.

\subsection{Acetic Acid}

Acetic acid is one of main components in fast pyrolysis oil [77]. It draws much attention as a model compound of pyrolysis oils for steam reforming to produce hydrogen [78]. As discussed earlier, APR process takes place at a milder temperature than steam reforming. Acetic acid has been mentioned as an intermediate and byproduct during the APR process of ethanol [72]. The stoichiometric equation of APR process of acetic acid is shown below.

$$
\mathrm{C}_{2} \mathrm{H}_{4} \mathrm{O}_{2}+2 \mathrm{H}_{2} \mathrm{O} \rightarrow 4 \mathrm{H}_{2}+2 \mathrm{CO}_{2}
$$

Nozawa et al. [72] studied the acetic acid according to the same reaction condition used in APR process of ethanol. Only one fourth of ethanol $\mathrm{TOF}_{\mathrm{H} 2}$ was achieved on acetic acid. The TOF for hydrogen and carbon dioxide was in a ratio of 2:1. According to their report, acetic acid underwent APR process at first 200 min, then changed to decomposition as it mentioned in the second pathway of ethanol. Xie et al. [76] reported that a 
maximum hydrogen selectivity of acetic acid was $66.67 \%$ and achieved hydrogen selectivity of 50\% using oxygen to reduce methanation and decomposition. No deactivation of catalyst has been found in any of the APR of acetic acid research papers.

\subsection{Biomass Hydrolysate}

Renewable biomass feedstock becomes attractive as fuel resource due to its environmentally friendly nature and its sufficient reduction of the dependence on fossil fuels [59]. Cellulose and hemicellulose, the two main components from lignocellulosic biomass, consist of chains of glucose and xylose unit, which can be used as the feedstock of APR process after hydrolysis [79]. Using biomass hydrolysate as feedstock for APR process has many advantages over the other hydrogen producing methods [27]. On one hand, compared with thermochemical methods, the biomass hydrolysate does not have to remove the water from the water-soluble feedstock. On the other hand, APR is conducted under mild conditions, usually at low temperatures, which minimize the undesirable decomposition of biomass feedstock.

Very few research aims on APR process of biomass hydrolysate [27] [59] [79]. The hydrolysis process on lignocellulosic biomass contains complicated reactions, turning a tough job to distinguish the chemical components and their content in details. The reaction pathways of hydrolysate for APR process include the pathways of glucose, fructose, xylose, polyols, ethanol and even acid, which result in variety of product and high carbon dioxide content in mixture gas. According to the experiment results [59] [79], biomass hydrolysate gives higher hydrogen selectivity and hydrogen yield per mass of carbohydrate than glucose on $\mathrm{Pt} / \mathrm{Al}_{2} \mathrm{O}_{3}$ catalyst, but much lower compared to glycerol. Some catalysts such as Raney Ni catalyst contribute to increase gas yield, while decrease the hydrogen yield dramatically [59]. Complex components in hydrolysate make it more difficult to control APR conditions than single component feedstock.

\section{Overall Aspects and Prospects}

Tremendous achievements have been scored on APR of renewable bio-based materials in laboratory perspectives in the last decade. The main barrier for APR process is to reduce the cost for hydrogen production. Currently, $96 \%$ of hydrogen is produced by steam reforming of fossil fuels with a cost in the range of 2 to 4 dollars per kg at industrial hydrogen production [12] [80]. Although huge efforts and money have been devoted, the cost of hydrogen production is still far from the target at treble times [80]. Since APR process still remains at lab-scale, further study on exploring highly effective and low cost catalysts to reduce the cost and produce more value-added liquid fuel products in industrial prospects is still necessary.

\subsection{Catalysts Innovation}

Noble metal catalysts like Pt, Ru and Pd are widely applied in APR process at lab-scales for their high activity towards C-C bond cleavage and less susceptible to reactions intermediates [81]. Obviously, noble metals cannot afford for large scale APR process due to its limited reserves and high cost. Ni, which is widely used in industrial hydrogen production, has a huge potential to take the place of noble metals. Compared with noble metals, Ni is much cheaper but reported having high alkane selectivity during the APR process [6]. The solution for the limitation of $\mathrm{Ni}$ is combining other metal with $\mathrm{Ni}$ and creating bimetallic catalysts. The APR processes of glucose, sorbitol, glycerol and ethylene glycol via $\mathrm{Ni}-\mathrm{Cu}, \mathrm{Ni}-\mathrm{Sn}$ bimetallic catalyst have been tested and obtained considerable hydrogen selectivity and yield equal to or even higher than noble metal [15] [27] [28] [58] [64] [70]. The metal added in the bimetallic catalyst is usually active in part of the APR process and has a low price. Cu is not involved during the C-C bond cleavage or dehydrogenation but promotes WGS towards hydrogen and carbon dioxide formation [15] [20]. Sn also promotes WGS reactions and turns the catalyst not to be sensitive to WHSV and pressure [64]. Though Ni based bimetallic catalyst is easily deactivated due to highly dispersed metal particles sintering and $\mathrm{NiO}$ hydration, the limitation has been overcome by using Al hydrotalcite support [27] [70]. The only problem requires more attention is the decrease in feedstock conversion percentage referring to Tuza et al. [15] and Pan et al. [70]. Higher temperatures are desirable for Ni based bimetallic catalysts in APR processes than Pt based catalyst [70].

Catalyst support plays an important role in APR process. Davda et al. [6] concluded that a higher impact on reforming activity and selectivity was caused by supports than metal catalysts. A good catalyst support of APR process should have large surface area but cannot be easily deactivated. The deactivation of catalysts may occur 
by hydrothermal degradation or strong adsorption to product. Shabaker et al. [21] had conducted experiment on Pt catalyst using different supports. $\mathrm{Al}_{2} \mathrm{O}_{3}$ was selected as the optimized choices for the highest hydrogen production and selectivity among all other supports tested. Supports like $\mathrm{CeO}_{2}, \mathrm{ZnO}$, and $\mathrm{SiO}_{2}$ were deactivated by hydrothermal degradation, while the others like $\mathrm{TiO}_{2}, \mathrm{SiO}_{2}-\mathrm{Al}_{2} \mathrm{O}_{3}$ led to alkane selectivity due to its acidity. New supports for hydrogen production require high stability and high surface area for reactions, but less barrier for reactants and products adsorbing and releasing. Based on development of $\mathrm{Al}$ based supports, $\mathrm{Al}$ hydrotalcite was applied by Pan et al. [70] and showed that it successfully maintained a high hydrogen production rate and a good hydrogen selectivity of $100 \%$ on $\mathrm{Sn}-\mathrm{Ni} / \mathrm{Al}$ hydrotalcite catalyst for over $120 \mathrm{~h}$. Fresh supports such as active carbon are found and tested. Kim et al. [18] [82] obtained $\mathrm{TOF}_{\mathrm{H} 2}$ of $30 \mathrm{~min}^{-1}$ from ethylene glycol via Pt catalyst on ordered mesoporous carbon support. Kim et al. held the point that mesoporous carbon structures contributed preventing metal sintering and transporting for both reactants and products.

\subsection{Alkane Selectivity}

Producing renewable alkanes from biomass resource is more environmentally friendly than current pathways from fossil fuels, as it reduces carbon dioxide emission [83]. The APR process can produce liquid alkanes ranging from C5 to C6 with reaction conditions carefully controlled [46]. It has been discussed above that C-C bond cleavage competes with C-O bond cleavage during the APR process. The C-O bond cleavage causes lower hydrogen selectivity. On the contrary, C-O bond cleavage results in deoxygenation and higher alkane selectivity. Referring to Cortright et al. [14] research, glucose and sorbitol had better alkane selectivity than other bio-based materials on APR process. On the opposite to hydrogen production, alkane production prefers using high alkane selectivity catalyst with acidic supports such as $\mathrm{TiO}_{2}, \mathrm{SiO}_{2}-\mathrm{Al}_{2} \mathrm{O}_{3}$, and ZSM-5. Huber et al. [24] found alkanes are formed by combining metal and acidic components, as lower $\mathrm{pH}$ of feedstock and solid-acid attributes to high alkane selectivity. Zhang et al. [46] conducted researches on liquid alkane production on APR process with sorbitol, and achieved maximum conversion of $67.1 \%$ and liquid alkane selectivity of $98.7 \%$ at $240^{\circ} \mathrm{C}$ and 4.0 MPa via $2 \% \mathrm{Ni} / \mathrm{HZSM}-5$ catalyst. Their work strongly proved a feasible pathway for liquid alkane production from renewable bio-based material.

\section{Conclusion}

Hydrogen produced from aqueous phase reforming (APR) of renewable biomass derived feedstock has been reviewed. Each bio-based material has its own APR pathway and kinetics. As a result, significant distinction on hydrogen selectivity and reaction limitations was discussed. Table 1 shows the overview of APR of different

Table 1. Overview of APR catalysts of different feedstock.

\begin{tabular}{|c|c|c|c|}
\hline \multirow{2}{*}{ Feedstock } & \multicolumn{2}{|c|}{ Catalysts } & \multirow{2}{*}{ Reference } \\
\hline & Metal & Support & \\
\hline Glucose & Pt, Ni, Ru, Rh-Pd, Ir & $\mathrm{Al}_{2} \mathrm{O}_{3}, \mathrm{TiO}_{2}, \mathrm{ZrO}_{2}, \mathrm{SiO}_{2}-\mathrm{Al}_{2} \mathrm{O}_{3}$ & $\begin{array}{c}\text { Davda et al. [32], Minowa et al. [36], } \\
\text { Tanksale et al. }\end{array}$ \\
\hline Fructose & $\mathrm{Pt}$ & $\mathrm{Al}_{2} \mathrm{O}_{3}$ & Kabyemela et al. [37] \\
\hline Sorbitol & Pt, Raney Ni-Sn, Ni-Pd & $\mathrm{Al}_{2} \mathrm{O}_{3}, \mathrm{TiO}_{2}, \mathrm{CeO}_{2}$ & $\begin{array}{l}\text { Davda et al. [6], Aiouache et al [25], } \\
\text { Huber et al. [48], Kirilin et al. [47] }\end{array}$ \\
\hline Xylitol & Pt, Pt-Re & $\mathrm{Al}_{2} \mathrm{O}_{3}, \mathrm{TiO}_{2}$ & Kirilin et al. [25] [47] \\
\hline Glycerol & Pt, Ni-Sn, Ni-Cu, Ni-B & $\mathrm{Al}_{2} \mathrm{O}_{3}, \mathrm{SiO}_{2}, \mathrm{ASA}$ & $\begin{array}{l}\text { Tuza et al. [15], Davda et al. [20], Shabaker } \\
\text { et al. [28] Guo et al. [58], Meryemoglu et al. } \\
\text { [59], Ciftci et al. [60], Özgür et al. [63] }\end{array}$ \\
\hline Ethylene Glycol & Pt, Ni, Ru, Rh-Pd, Pt-Co, Ni-Sn & $\begin{array}{l}\mathrm{Al}_{2} \mathrm{O}_{3}, \mathrm{SiO}_{2}, \mathrm{CNK}-3 \\
\quad \text { Al Hydrotalcite }\end{array}$ & $\begin{array}{l}\text { Davda et al., Huber et al., Dumesic et al. [6] } \\
\text { [14] [20] [21] [24] [26] [28] [35] [67], Kim et } \\
\text { al. [68], Chu et al. [69], Pan et al. [70] }\end{array}$ \\
\hline Ethanol & $\mathrm{Pt}, \mathrm{Ru}, \mathrm{Ni}$ & $\mathrm{Al}_{2} \mathrm{O}_{3}, \mathrm{SiO}_{2}, \mathrm{TiO}_{2}$ & $\begin{array}{l}\text { Tokarev et al. [71], Nozawa et al. [72], } \\
\text { Roy et al. [73]-[75] }\end{array}$ \\
\hline Methanol & Pt & $\mathrm{Al}_{2} \mathrm{O}_{3}$ & Shabaker et al. [67], Xie et al. [76] \\
\hline Acetic Acid & $\mathrm{Pt}$ & $\mathrm{Al}_{2} \mathrm{O}_{3}$ & Nozawa et al. [72], Xie et al. [76] \\
\hline Biomass Hydrolysate & Pt, Raney Ni & $\mathrm{Al}_{2} \mathrm{O}_{3}$ & Meryemoglu et al. [59] \\
\hline
\end{tabular}


feedstock. The usage of catalyst should be judged by feedstock on its requirement including C-C bond cleavage, water-gas shift (WGS) reaction and catalyst maintenance. Review shows that polyols with less carbon number exhibit a better hydrogen yield and selectivity than polyols with larger carbon numbers, such as sugars and other bio-based material. The economic analysis of APR process implies needs required for reducing the cost and producing more valuable products. Current reports on APR process are driving the directions of improving catalyst activity by using bimetallic catalysts and modified supports, taking advantage of the alkane selectivity of feedstock, and producing value-added chemicals.

\section{Acknowledgements}

The study was supported in partial by the Joint Center for Aerospace and Technology Innovation (JCATI) and Chinese Scholarship Councils.

\section{References}

[1] Preciado, J. (2013) Short-Term Energy Outlook Market Prices and Uncertainty Report. US Department of Energy EIA, US Government. http://www.eia.gov/forecasts/steo/uncertainty/

[2] Balat, M. and Balat, M. (2009) Political, Economic and Environmental Impacts of Biomass-Based Hydrogen. International Journal of Hydrogen Energy, 34, 3589-3603. http://dx.doi.org/10.1016/j.ijhydene.2009.02.067

[3] Bu, Q., Lei, H., Zacher, A.H., Wang, L., Ren, S., Liang, J., Wei, Y., Liu, Y., Tang, J., Zhang, Q. and Ruan, R. (2012) A Review of Catalytic Hydrodeoxygenation of Lignin-Derived Phenols from Biomass Pyrolysis. Bioresource Technology, 124, 470-477. http://dx.doi.org/10.1016/j.biortech.2012.08.089

[4] Basagiannis, A.C. and Verykios, X.E. (2007) Catalytic Steam Reforming of Acetic Acid for Hydrogen Production. International Journal of Hydrogen Energy, 32, 3343-3355. http://dx.doi.org/10.1016/j.ijhydene.2007.04.039

[5] Nigam, P.S. and Singh, A. (2010) Production of Liquid Biofuels from Renewable Resources. Progress in Energy and Combustion Science, 37, 52-68. http://dx.doi.org/10.1016/j.pecs.2010.01.003

[6] Davda, R.R., Shabaker, J.W., Huber, G.W., Cortright, R.D. and Dumesic, J.A. (2005) A Review of Catalytic Issues and Process Conditions for Renewable Hydrogen and Alkanes by Aqueous-Phase Reforming of Oxygenated Hydrocarbons over Supported Metal Catalysts. Applied Catalysis B: Environmental, 56, 171-186. http://dx.doi.org/10.1016/j.apcatb.2004.04.027

[7] Kirtay, E. (2011) Recent Advances in Production of Hydrogen from Biomass. Energy Conversion and Management, 52, 1778-1789. http://dx.doi.org/10.1016/j.enconman.2010.11.010

[8] Demirbas, A. (2009) Emission Characteristics of Gasohol and Diesohol. Energy Source A, 31, 1099-1104. http://dx.doi.org/10.1080/10916460801907120

[9] Demirbas, M.F., Balat, M. and Balat, H. (2009) Potential Contribution of Biomass to the Sustainable Energy Development. Energy Conversion and Management, 50, 1746-1760. http://dx.doi.org/10.1016/j.enconman.2009.03.013

[10] Balat, M. (2008) Mechanisms of Thermochemical Biomass Conversion Processes. Part 3: Reactions of Liquefaction. Energy Source A, 30, 649-659.

[11] Balat, M. (2009) Development of Worldwide Green Electricity in the Past Decade. Energy Source B, 4, 17-33. http://dx.doi.org/10.1080/15567240802458575

[12] Holladay, J.D., Hu, J., King, D.L. and Wang, Y. (2009) An Overview of Hydrogen Production Technologies. Catalysis Today, 139, 244-260. http://dx.doi.org/10.1016/j.cattod.2008.08.039

[13] Adhikari, S., Fernando, S.D. and Haryanto, A. (2009) Hydrogen Production from Glycerol: An Update. Energy Convers Manage, 40, 2600-2604. http://dx.doi.org/10.1016/j.enconman.2009.06.011

[14] Cortright, R.D., Davda, R.R. and Dumesic, J.A. (2002) Hydrogen from Catalytic Reforming of Biomass-Derived Hydrocarbons in Liquid Water. Nature, 418, 964-967. http://dx.doi.org/10.1038/nature01009

[15] Tuza, P.V., Manfro, R.L., Ribeiro, N.F.P. and Souza, M.M.V.M. (2013) Production of Renewable Hydrogen by Aqueous-Phase Reforming of Glycerol over Ni-Cu Catalysts Derived from Hydrotalcite Precursors. Renewable Energy, 50, 408-414. http://dx.doi.org/10.1016/j.renene.2012.07.006

[16] Oh, S.E. and Logan, B.E. (2007) Voltage Reversal during Microbial Fuel Cell Stack Operation. Journal of Power Sources, 167, 11-17. http://dx.doi.org/10.1016/j.jpowsour.2007.02.016

[17] Aiouache, F., McAleer, L., Gan, Q., Al-Muhtaseb, A.H. and Ahmad, M.N. (2013) Path Lumping Kinetic Model for Aqueous Phase Reforming of Sorbitol. Applied Catalysis A: General, 466, 240-255.

http://dx.doi.org/10.1016/j.apcata.2013.06.039 
[18] Kim, T., Kim, H., Jeong, K., Chae, H., Jeong, S., Lee, C. and Kim, C. (2011) Catalytic Production of Hydrogen through Aqueous Phase Reforming over Platinum/Ordered Mesoporous Carbon Catalysts. Green Chemistry, 13, 17181728. http://dx.doi.org/10.1039/c1gc15235a

[19] Rhodes, C., Huchings, G.J. and Ward, A.M. (1995) Water-Gas Shift Reaction: Finding the Mechanistic Boundary. Catalysis Today, 23, 43-58. http://dx.doi.org/10.1016/0920-5861(94)00135-O

[20] Davda, R.R., Shabaker, J.W., Huber, G.W., Cortright, R.D. and Dumesic, J.A. (2003) Aqueous-Phase Reforming of Ethylene Glycol on Silica-Supported Metal Catalysts. Applied Catalysis B: Environmental, 43, 13-26. http://dx.doi.org/10.1016/S0926-3373(02)00277-1

[21] Shabaker, J.W., Huber, G.W., Davda, R.R., Cortright, R.D. and Dumesic, J.A. (2003) Aqueous-Phase Reforming of Ethylene Glycol over Supported Platinum Catalysts. Catalysis Letters, 88, 1-8. http://dx.doi.org/10.1023/A:1023538917186

[22] Li, N. and Huber, G. (2010) Aqueous-Phase Hydrodeoxygenation of Sorbitol with $\mathrm{Pt} / \mathrm{SiO}_{2}-\mathrm{Al}_{2} \mathrm{O}_{3}$ : Identification of Reaction Intermediates. Journal of Catalysis, 270, 48-59. http://dx.doi.org/10.1016/j.jcat.2009.12.006

[23] Lin, Y. and Huber, G. (2009) The Critical Role of Heterogenous Catalysis in Lignocellulosic Biomass Conversion. Energy \& Environmental Science, 2, 68-80. http://dx.doi.org/10.1039/b814955k

[24] Huber, G.W. and Dumesic, J.A. (2006) An Overview of Aqueous-Phase Catalytic Processes for Production of Hydrogen and Alkanes in a Biorefinery. Catalysis Today, 111, 119-132. http://dx.doi.org/10.1016/j.cattod.2005.10.010

[25] Kirilin, A.V., Tokarev, A.V., Kustov, L.M., Salmi, T., Mikkola, J.P. and Murzin, D.Y. (2012) Aqueous Phase Reforming of Xylitol and Sorbitol: Comparison and Influence of Substrate Structure. Applied Catalysis A: General, 435-436, 172-180. http://dx.doi.org/10.1016/j.apcata.2012.05.050

[26] Huber, G.W., Shabaker, J.W., Evans, S.T. and Dumesic, J.A. (2006) Aqueous-Phase Reforming of Ethylene Glycol over Supported Pt and Pd Bimetallic Catalysts. Applied Catalysis B: Environmental, 62, 226-235. http://dx.doi.org/10.1016/j.apcatb.2005.07.010

[27] Meryemoglu, B., Hesenov, A., Irmak, S., Atanur, O.M. and Erbatur, O. (2010) Aqueous-Phase Reforming of Biomass Using Various Types of Supported Precious Metal and Raney-Nickel Catalysts for Hydrogen Production. International Journal of Hydrogen Energy, 35, 12580-12587. http://dx.doi.org/10.1016/j.ijhydene.2010.08.046

[28] Shabaker, J.W., Simonetti, D.A., Cortright, R.D. and Dumesic, J.A. (2005) Sn-Modified Ni Catalysts for AqueousPhase Reforming: Characterization and Deactivation Studies. Journal of Catalysis, 231, 67-76. http://dx.doi.org/10.1016/j.jcat.2005.01.019

[29] Bimbela, F., Chen, D., Ruiz, J., García, L. and Arauzo, J. (2012) Ni/Al Coprecipitated Catalysts Modified with Magnesium and Copper for the Catalytic Steam Reforming of Model Compounds from Biomass Pyrolysis Liquids. Applied Catalysis B: Environmental, 119-120, 1-12. http://dx.doi.org/10.1016/j.apcatb.2012.02.007

[30] Roy, B., Sullivan, H. and Leclerc, C.A. (2011) Aqueous-Phase Reforming of n-BuOH over Ni/ $\mathrm{Al}_{2} \mathrm{O}_{3}$ and $\mathrm{Ni} / \mathrm{CeO}_{2}$ Catalysts. Journal of Power Sources, 196, 10652-10657. http://dx.doi.org/10.1016/j.jpowsour.2011.08.093

[31] Zhang, L., Karim, A.M., Engelhard, M.H., Wei, Z., King, D.L. and Wang, Y. (2012) Correlation of Pt-Re Surface Properties with Reaction Pathways for the Aqueous-Phase Reforming of Glycerol. Journal of Catalysis, 287, 37-43. http://dx.doi.org/10.1016/j.jcat.2011.11.015

[32] Davda, R.R. and Dumesic, J.A. (2004) Renewable Hydrogen by Aqueous-Phase Reforming of Glucose. Chemical Communication, Issue 1, 36-37. http://dx.doi.org/10.1039/b310152e

[33] Pińkowska, H., Wolak, P. and Oliveros, E. (2013) Production of Xylose and Glucose from Rapeseed Straw in Subcritical Water-Use of Doehlert Design for Optimizing the Reaction Conditions. Biomass and Bioenergy, 58, 188-197. http://dx.doi.org/10.1016/j.biombioe.2013.09.005

[34] Tanksale, A., Beltramini, J.N. and Lu, G.M. (2010) A Review of Catalytic Hydrogen Production Processes from Biomass. Renewable and Sustainable Energy Reviews, 14, 166-182. http://dx.doi.org/10.1016/j.rser.2009.08.010

[35] Gursahani, K.I., Alcala, R., Cortright, R.D. and Dumesic, J.A. (2001) Reaction Kinetics Measurements and Analysis of Reaction Pathways for Conversions of Acetic Acid, Ethanol, and Ethyl Acetate over Silica-Supported Pt. Applied Catalysis A: General, 222, 369-392. http://dx.doi.org/10.1016/S0926-860X(01)00844-4

[36] Minowa, T. and Ogi, T. (1998) Hydrogen Production from Cellulose Using a Reduced Nickel, Catalyst. Catalysis Today, 45, 411-416.http://dx.doi.org/10.1016/S0920-5861(98)00277-6

[37] Tanksale, A., Beltramini, J.N. and Lu, G.Q. (2006) Reaction Mechanisms for Renewable Hydrogen from Liquid Phase Reforming of Sugar Compounds. Developments in Chemical Engineering and Mineral Processing, 14, 9-18. http://dx.doi.org/10.1002/apj.5500140102

[38] Kabyemela, B.M., Adschiri, T., Malaluan, R.M. and Arai, K. (1999) Glucose and Fructose Decomposition in Subcritical and Supercritical Water: Detailed Reaction Pathway, Mechanisms, and Kinetics. Industrial \& Engineering Chemi- 
stry Research, 38, 2888-2895. http://dx.doi.org/10.1021/ie9806390

[39] Kanie, Y., Akiyama, K. and Iwamoto, M. (2011) Reaction Pathways of Glucose and Fructose on Pt Nanoparticles in Subcritical Water under a Hydrogen Atmosphere. Catalysis Today, 178, 58-63. http://dx.doi.org/10.1016/j.cattod.2011.07.031

[40] Zhang, J., Xu, S., Wu, S. and Liu, Y. (2013) Hydrogenation of Fructose over Magnetic Catalyst Derived from Hydrotalcite Precursor. Chemical Engineering Science, 99, 171-176. http://dx.doi.org/10.1016/j.ces.2013.06.002

[41] Flego, C., Carati, A. and Perego, C. (2001) Methanol Interaction with Mesoporous Silica-Aluminas. Microporous and Mesoporous Materials, 44-45, 733-744. http://dx.doi.org/10.1016/S1387-1811(01)00255-4

[42] Tanksale, A., Beltramini, J.N., Dumesic, J.A. and Lu, G.Q. (2008) Effect of Pt and Pd promoter on Ni Supported Catalysts-A TPR/TPO/TPD and Microcalorimetry Study. Journal of Catalysis, 258, 366-377. http://dx.doi.org/10.1016/j.jcat.2008.06.024

[43] Silveira, M.M. and Jonas, R. (2004) Sorbitol Can Be Produced Not Only Chemically but Also Biotechnologically. Applied Biochemistry and Biotechnology, 118, 321-336. http://dx.doi.org/10.1385/ABAB:118:1-3:321

[44] Li, N., Tompsett, G.A., Zhang, T.Y., Shi, J.A., Wyman, C.E. and Huber, G.W. (2011) Renewable Gasoline from Aqueous Phase Hydrodeoxygenation of Aqueous Sugar Solutions Prepared by Hydrolysis of Maple Wood. Green Chemistry, 13, 91-101. http://dx.doi.org/10.1039/c0gc00501k

[45] Liu, C., Dong, H., Zhong, J., Ryu, D.D.Y. and Bao, J. (2010) Sorbitol Production Using Recombinant Zymomonas Mobilis Strain. Journal of Biotechnology, 148, 105-112.

[46] Zhang, Q., Wang, T., Xu, Y., Zhang, Q. and Ma, L. (2014) Production of Liquid Alkanes by Controlling Reactivity of Sorbitol Hydrogenation with a Ni/HZSM-5 Catalyst in Water. Energy Conversion and Management, 77, 262-268. http://dx.doi.org/10.1016/j.enconman.2013.09.032

[47] Kirilin, A.V., Tokarev, A.V., Murzina, E.V., Kustov, L.M., Mikkola, J.P. and Murzin, D.Y. (2010) Reaction Products and Transformations of Intermediates in the Aqueous Phase Reforming of Sorbitol. ChemSusChem, 3, 708-718. http://dx.doi.org/10.1002/cssc.200900254

[48] Huber, G.W., Shabaker, J.W. and Dumesic, J.A. (2003) Raney Ni-Sn Catalyst for $\mathrm{H}_{2}$ from Biomass-Derived Hydrocarbons. Science, 300, 2075-2077. http://dx.doi.org/10.1126/science.1085597

[49] Li, Z., Qu, H., Li, C. and Zhou, X. (2013) Direct and Efficient Xylitol Production from Xylan by Saccharomyces cerevisiae through Transcriptional Level and Fermentation Processing Optimizations. Bioresource Technology, 149, 413419. http://dx.doi.org/10.1016/j.biortech.2013.09.101

[50] Wisniak, J., Hershkowitz, M., Leibowitz, R. and Stein, S. (1974) Hydrogenation of Xylose to Xylitol. Industrial \& Engineering Chemistry Product Research and Development, 13, 75-79. http://dx.doi.org/10.1021/i360049a015

[51] Kirilin, A.V., Tokarev, A.V., Manyar, H., Hardacre, C., Salmi, T., Mikkola, J.P. and Murzin, D.Y. (2013) Aqueous Phase Reforming of Xylitol over Pt-Re Bimetallic Catalyst: Effect of the Re Addition. Catalysis Today, 215, 97-107. http://dx.doi.org/10.1016/j.cattod.2013.09.020

[52] Jiang, T., Wang, T., Ma, L., Li, Y., Zhang, Q. and Zhang, X. (2012) Investigation on the Xylitol Aqueous-Phase Reforming Performance for Pentane Production over Pt/HZSM-5 and Ni/HZSM-5 Catalysts. Applied Energy, 90, 51-57. http://dx.doi.org/10.1016/j.apenergy.2011.03.034

[53] Ayoub, M. and Abdullah, A.Z. (2012) Critical Review on the Current Scenario and Significance of Crude Glycerol Resulting from Biodiesel Industry towards More Sustainable Renewable Energy Industry. Renewable and Sustainable Energy Reviews, 16, 2671-2686. http://dx.doi.org/10.1016/j.rser.2012.01.054

[54] Selembo, P.A., Perez, J.M., Lloyd, W.A. and Logan, B.E. (2009) High Hydrogen Production from Glycerol or Glucose by Electrohydrogenesis Using Microbial Electrolysis Cells. International Journal of Hydrogen Energy, 34, 5373-5381. http://dx.doi.org/10.1016/j.ijhydene.2009.05.002

[55] Souza, A.C.C. and Silveira, J.L. (2011) Hydrogen Production Utilizing Glycerol from Renewable Feedstocks-The Case of Brazil. Renewable and Sustainable Energy Reviews, 15, 1835-1850. http://dx.doi.org/10.1016/j.rser.2010.12.001

[56] Luo, N., Fu, X., Cao, F., Xiao, T. and Edwards, P.P. (2008) Glycerol Aqueous Phase Reforming for Hydrogen Generation over Pt Catalyst-Effect of Catalyst Composition and Reaction Conditions. Fuel, 87, 3483-3489. http://dx.doi.org/10.1016/j.fuel.2008.06.021

[57] Wawrzetz, A., Peng, B., Hrabar, A., Jentys, A., Lemonidou, A.A. and Lerche, J.A. (2010) Towards Understanding the Bifunctional Hydrodeoxygenation and Aqueous Phase Reforming of Glycerol. Journal of Catalysis, 269, 411-420. http://dx.doi.org/10.1016/j.jcat.2009.11.027

[58] Guo, Y., Liu, X., Azmat, M.U., Xu, W., Ren, J., Wang, Y. and Lu, G. (2012) Hydrogen Production by Aqueous-Phase Reforming of Glycerol over Ni-B Catalysts. International Journal of Hydrogen Energy, 37, 227-234. 
http://dx.doi.org/10.1016/j.ijhydene.2011.09.111

[59] Meryemoglu, B., Kaya, B., Irmak, S., Hesenov, A. and Erbatur, O. (2012) Comparison of Batch Aqueous-Phase Reforming of Glycerol and Lignocellulosic Biomass Hydrolysate. Fuel, 97, 241-244. http://dx.doi.org/10.1016/j.fuel.2012.02.011

[60] Ciftci, A., Peng, B., Jentys, A., Lercher, J.A. and Hensen, E.J.M. (2012) Support Effects in the Aqueous Phase Reforming of Glycerol over Supported Platinum Catalysts. Applied Catalysis A: General, 431-432, 113-119. http://dx.doi.org/10.1016/j.apcata.2012.04.026

[61] Menezes, A.O., Rodrigues, M.T., Zimmaro, A., Borges, L.E.P. and Fraga, M.A. (2011) Production of Renewable Hydrogen from Aqueous-Phase Reforming of Glycerol over Pt Catalysts Supported on Different Oxides. Renewable Energy, 36, 595-599. http://dx.doi.org/10.1016/j.renene.2010.08.004

[62] Copeland, J.R., Foo, G.S., Harrison, L.A. and Sievers, C. (2013) In Situ ATR-IR Study on Aqueous Phase Reforming Reactions of Glycerol over a Pt/ $\gamma-\mathrm{Al}_{2} \mathrm{O}_{3}$ Catalyst. Catalysis Today, 205, 49-59. http://dx.doi.org/10.1016/j.cattod.2012.08.002

[63] Özgür, D. and Uysal, B.Z. (2011) Hydrogen Production by Aqueous Phase Catalytic Reforming of Glycerine. Biomass and Bioenergy, 35, 822-826. http://dx.doi.org/10.1016/j.biombioe.2010.11.012

[64] Xie, F., Chu, X., Hu, H., Qiao, M., Yan, S., Zhu, Y., He, H., Fan, K., Li, H., Zong, B. and Zhang, X. (2006) Characterization and Catalytic Properties of Sn-Modified Rapidly Quenched Skeletal Ni Catalysts in Aqueous-Phase Reforming of Ethylene Glycol. Journal of Catalysis, 241, 211-220. http://dx.doi.org/10.1016/j.jcat.2006.05.001

[65] Vlieger, D.J.M., Mojet, B.L., Lefferts, L. and Seshan, K. (2012) Aqueous Phase Reforming of Ethylene Glycol—Role of Intermediates in Catalyst Performance. Journal of Catalysis, 292, 239-245. http://dx.doi.org/10.1016/j.jcat.2012.05.019

[66] Alcala, R., Mavrikakis, M. and Dumesic, J.A. (2003) DFT Studies for Cleavage of C-C and C-O Bonds in Surface Species Derived from Ethanol on Pt (111). Journal of Catalysis, 218, 178-190. http://dx.doi.org/10.1016/S0021-9517(03)00090-3

[67] Shabaker, J.W., Davda, R.R., Huber, G.W., Cortright, R.D. and Dumesic, J.A. (2003) Aqueous-Phase Reforming of Methanol and Ethylene Glycol over Alumina-Supported Platinum Catalysts. Journal of Catalysis, 215, 344-352. http://dx.doi.org/10.1016/S0021-9517(03)00032-0

[68] Kim, H., Park, H., Kim, T., Jeong, K., Chae, H., Jeong, S., Lee, C. and Kim, C. (2012) Hydrogen Production through the Aqueous Phase Reforming of Ethylene Glycol over Supported Pt-Based Bimetallic Catalysts. International Journal of Hydrogen Energy, 37, 8310-8317.

[69] Chu, X., Liu, J., Sun, B., Dai, R., Pei, Y., Qiao, M. and Fan, K. (2011) Aqueous-Phase Reforming of Ethylene Glycol on Co/ZnO Catalysts Prepared by the Coprecipitation Method. Journal of Molecular Catalysis A: Chemical, 335, 129135. http://dx.doi.org/10.1016/j.molcata.2010.11.024

[70] Pan, G., Ni, Z., Cao, F. and Li, X. (2012) Hydrogen Production from Aqueous-Phase Reforming of Ethylene Glycol over Ni/Sn/Al Hydrotalcite Derived Catalysts. Applied Clay Science, 58, 108-113. http://dx.doi.org/10.1016/j.clay.2012.01.023

[71] Tokarev, A.V., Kirilin, A.V., Murzina, E.V., Eränen, K., Kustov, L.M., Murzin, D.Y. and Mikkola, J.P. (2010) The Role of Bio-Ethanol in Aqueous Phase Reforming to Sustainable Hydrogen. International Journal of Hydrogen Energy, 35, 12642-12649. http://dx.doi.org/10.1016/j.ijhydene.2010.07.118

[72] Nozawa, T., Mizukoshi, Y., Yoshida, A. and Naito, S. (2014) Aqueous Phase Reforming of Ethanol and Acetic Acid over $\mathrm{TiO}_{2}$ Supported Ru Catalysts. Applied Catalysis B: Environmental, 146, 221-226. http://dx.doi.org/10.1016/j.apcatb.2013.06.017

[73] Roy, B., Loganathan, K., Pham, H.N., Datye, A.K. and Leclerc, C.A. (2010) Surface Modification of Solution Combustion Synthesized $\mathrm{Ni} / \mathrm{Al}_{2} \mathrm{O}_{3}$ Catalyst for Aqueous-Phase Reforming of Ethanol. International Journal of Hydrogen Energy, 35, 11700-11708. http://dx.doi.org/10.1016/j.ijhydene.2010.07.167

[74] Roy, B., Martinez, U., Loganathan, K., Datye, A.K. and Leclerc, C.A. (2012) Effect of Preparation Methods on the Performance of $\mathrm{Ni} / \mathrm{Al}_{2} \mathrm{O}_{3}$ Catalysts for Aqueous-Phase Reforming of Ethanol: Part I-Catalytic Activity. International Journal of Hydrogen Energy, 37, 8143-8153. http://dx.doi.org/10.1016/j.ijhydene.2012.02.056

[75] Roy, B., Artyushkova, K., Pham, H.N., Li, L., Datye, A.K. and Leclerc, C.A. (2012) Effect of Preparation Method on the Performance of the $\mathrm{Ni} / \mathrm{Al}_{2} \mathrm{O}_{3}$ Catalysts for Aqueous-Phase Reforming of Ethanol: Part II-Characterization. International Journal of Hydrogen Energy, 37, 18815-18826. http://dx.doi.org/10.1016/j.ijhydene.2012.09.098

[76] Xie, J., Su, D., Yin, X., Wu, C. and Zhu, J. (2011) Thermodynamic Analysis of Aqueous Phase Reforming of Three Model Compounds in Bio-Oil for Hydrogen Production. International Journal of Hydrogen Energy, 36, 15561-15572. http://dx.doi.org/10.1016/j.ijhydene.2011.08.103 
[77] Basagiannis, A.C. and Verykios, X.E. (2007) Catalytic Steam Reforming of Acetic Acid for Hydrogen Production. International Journal of Hydrogen Energy, 32, 3343-3355. http://dx.doi.org/10.1016/j.ijhydene.2007.04.039

[78] Bimbela, F., Oliva, M., Ruiz, J., Garcia, L. and Arauzo, J. (2007) Hydrogen Production by Catalytic Steam Reforming of Acetic Acid, a Model Compound of Biomass Pyrolysis Liquids. Journal of Analytical and Applied Pyrolysis, 79, 112-120. http://dx.doi.org/10.1016/j.jaap.2006.11.006

[79] Valenzuela, M.B., Jones, C.W. and Agrawal, P.K. (2006) Batch Aqueous-Phase Reforming of Woody Biomass. Energy \& Fuels, 20, 1744-1752. http://dx.doi.org/10.1021/ef060113p

[80] Geantet, C. and Guilhaume, N. (2008) Hydrogen Production from Biomass. In Vanatrop, 22-24 October 2008, Montpellier.

[81] Soares, R.R., Simonetti, D.A. and Dumesic, J.A. (2006) Glycerol as a Source for Fuels and Chemicals by Low-Temperature Catalytic Processing. Angewandte Chemie International Edition, 45, 3982-3985. http://dx.doi.org/10.1002/anie.200600212

[82] Kim, H., Kim, T., Park, H., Jeong, K., Chae, H., Jeong, S., Lee, C. and Kim, C. (2012) Hydrogen Production via the Aqueous Phase Reforming of Ethylene Glycol over Platinum-Supported Ordered Mesoporous Carbon Catalysts: Effect of Structure and Framework-Configuration. International Journal of Hydrogen Energy, 37, 12187-12197. http://dx.doi.org/10.1016/j.ijhydene.2012.05.126

[83] Baliban, R.C., Elia, J.A. and Floudas, C.A. (2013) Biomass to Liquid Transportation Fuels (BTL) Systems: Process Synthesis and Global Optimization Framework. Energy \& Environmental Science, 6, 267-287. http://dx.doi.org/10.1039/c2ee23369j 